\title{
Redes sociais em contextos escolares: convergências e divergências quanto ao conceito e uso
}

\author{
Angela Noleto da Silva* \\ Katia Cristina Custódio Ferreira Brito** \\ Rosilene Lagares ${ }^{* * *}$
}

\begin{abstract}
Resumo
Com a intensificação do acesso às vias digitais e a aquisição dos artefatos tecnológicos móveis por todos os segmentos da sociedade, os canais de comunicação em massa passaram a fazer parte do cotidiano contemporâneo. $\mathrm{O}$ artigo apresenta resultados da primeira etapa de pesquisa longitudinal que visa a compreender a inserção das tecnologias da informação, comunicação e expressão (TICE) em espaços escolares públicos. O objetivo é apresentar percepções de docentes e discentes acerca das Redes Sociais de Comunicação como um meio pedagógico auxiliador de estratégias de estudos na organização do trabalho docente e discente. Com abordagem qualitativa e dados coletados por meio de revisão bibliográfica e aplicação de questionários semiestruturados, apresenta reflexões oriundas de investigação realizada em um Centro de Ensino Médio no Estado do Tocantins, delimitando como sujeitos da pesquisa docentes e discentes. Os estudos indicam que as transformações que ocorrem nos tempos-espaços multimodais de formação humana, em especial o espaço escolar, apresentam posturas diversas em sala de aula e ações individuais e coletivas expressas pelos sujeitos investigados que ora convergem e ora divergem seus olhares quanto às possibilidades do uso pedagógico das vias digitais de comunicação. Conclui-se que há divergências na percepção pedagógica do uso das redes sociais em contextos escolares.
\end{abstract}

Palavras-chave: tecnologia e educação, sociedade da informação, ensino médio, redes sociais e educação.

Social networks in school contexts: convergences and divergences regarding the concept and use

Abstract

With the intensification of access to digital channels and the acquisition of mobile devices by all segments of society, mass communication channels have become part of contemporary daily life. The article presents results from the first stage of longitudinal research that aims to understand the use of information, communication and expression technologies (TICE) in public school spaces. The objective is to present teachers 'and students' perceptions about Social Communication Networks as a pedagogical medium that supports study strategies in the organization of teaching and student work. With a qualitative approach and data collected through bibliographic review and application of semi-structured questionnaires, it presents reflections arising from research executed in a High School Center in the State of Tocantins, delimiting teachers and students as research subjects. The studies indicate that the transformations that occur in multimodal times-spaces of human formation, especially the school space, present different postures in the classroom and individual and collective actions expressed by the investigated subjects who sometimes converge and sometimes diverge their views regarding the possibilities pedagogical use of digital communication channels. Conclusively, there are divergences in the pedagogical perception on the use of social networks in school contexts.

Keywords: technology and education, information society, high school, social networks and education.

\footnotetext{
* Doutoranda no Programa de Pós-Graduação em Educação (PPGE/UNB) da Universidade de Brasília. Mestre em Educação pela Universidade Federal de Goiás (UFG). Docente do curso de Pedagogia da Universidade Federal do Tocantins. Pesquisadora na área de Educação Tecnologias e Comunicação. Email: angelanoleto@uft.edu.br.

** Doutora em Educação pela UFSCcar. Professora na Universidade Federal do Tocantins. E-mail: katiacristina@uft.edu.br.

**** Doutora em Educação pela UFG. Professora da Universidade Federal do Tocantins (UFT)/Campus de Palmas: Curso de Pedagogia, Programa de Pós Graduação em Educação - Mestrado acadêmico e Doutorado em Educação na Amazônia (EDUCANORTE). E-mail: lagaresrose@ gmail.com.
} 


\section{Introdução}

$\mathrm{Na}$ contemporaneidade, observa-se a consolidação de uma sociedade da informação (CASTELLS, 1999), em que delineamentos iniciais ocorreram, expressivamente, nas últimas décadas do século XX e início da primeira década de século XXI. Os traços marcantes desse século atrelam-se ao avanço em pesquisas no campo da nanotecnologia, biotecnologia, globalização de mercados, redimensionamentos geopolíticos, elaboração/manipulação dos artefatos tecnológicos digitais e na potencialização dos meios midiáticos (TV, celulares, notebooks, tablets, iphones, ipads, Internet, rádio online, plataformas de aprendizagem online) como trilha para a ampliação das diversificadas maneiras de comunicação.

Nessa esteira de mudanças, os diversos segmentos educacionais e, em especial, os profissionais que atuam nas escolas públicas brasileiras, são desafiados a compreender quem são os sujeitos e fazeres da contemporaneidade. Além disso, também são desafiados a analisarem as novas formas de linguagens, as concepções e produção de conhecimentos que vão se forjando nesses novos ambientes de aprendizagens, nos processos de (re)elaboração de linguagens, de escrita e organização do trabalho escolar que já possuem ou passam a adotar, face à sua imersão e adesão a essa nova realidade, como destaca Rojo (2012, p. 99):

\footnotetext{
A chegada cada vez mais rápida e intensa das tecnologias (com o uso cada vez mais comum de computadores, Ipods, celulares, tablets, etc.) e de novas práticas sociais de leitura e de escrita (condizentes com os acontecimentos contemporâneos e com os textos multissemióticos circulantes) requer da escola trabalhos focados nessa realidade.
}

Assiste-se, cotidianamente, a uma nova configuração nas formas múltiplas e singulares de produção e elaboração de conhecimentos, em que os campos da educação e tecnologia de informação e comunicação (TICE), têm estreitado laços para o desenvolvimento e aprimoramento de metodologias e práticas docentes. Encontra-se, de forma mais intensificada, a utilização de recursos tecnológicos digitais como ampliação comunicacional, acesso a instrumentos/uso das ferramentas de interação homem/máquina, homem/homem que auxiliam na troca de informações, dados e socialização entre os jovens, a destacar os nascidos ao final da década de 1990, representantes dos denominados "nativos digitais" (PRENSKI, 2001), cuja familiaridade 
tecnológica compõe suas maneiras de ser, conviver e identificar-se com os outros e com o mundo.

A denominação, "nativos digitais e imigrantes" foi cunhada por Prenski (2001), para descrever os usuários das tecnologias digitais, sendo o primeiro, caracterizado por aqueles que nasceram em um universo digital, em contato contínuo com a Rede Mundial de Computadores - Internet, e encaram com facilidade as frequentes mudanças, novidades do mundo tecnológico, além de se adaptarem com extrema facilidade a essa nova realidade. Os imigrantes digitais são aqueles que sistematicamente introduzem em sua cotidianidade essas novas maneiras de interlocução entre linguagem, comunicação, veiculação de informações e conhecimentos.

Tapscott (2010) destaca que a Geração Net, cresce e convive cercada de um manancial de objetos técnicos e aplicativos capazes de criar redes de conexões com o mundo, levando à compreensão de que fazer uso da Rede pressupõe acessar uns aos outros. Em status online, diariamente inalterado, essa geração de jovens distingue-se das anteriores por moldar suas vontades, prazeres, interesses, consumir incessantemente saberes, produtos de toda ordem e lugar, mas sempre em cadência com o ritmo estabelecido pela produção de informações e, por conseguinte, por demonstrar capacidade de se posicionar, opinar, tomar decisões, contudo, sem conseguir evitar os conflitos inerentes às transformações sociais, econômicas, culturais, políticas e educacionais que emolduram a sociedade tecnocapitalista.

A par desse cenário, evidencia-se, no campo acadêmico, a importância de se investigar, questionar e realizar análises a respeito dos fenômenos socioculturais que ora se engendram por meio da digitalização das relações sociais, sua imersão e implicações no campo educacional, tomando como referência a percepção que docentes e discentes possuem acerca do uso das redes sociais. Ademais, torna-se necessário investigar as contribuições pedagógicas possíveis no sentido de tornar as redes sociais elementos integradores ao que a escola propõe frente aos seus objetivos educacionais, às práticas de ensino e aprendizagem e ao interesse que esses atores, os identificados como nativos e/ou imigrantes digitais (PRENSKI, 2001), sugerem.

É nesse cenário, que este artigo apresenta resultados da primeira etapa de pesquisa longitudinal visando compreender a inserção das tecnologias da informação, comunicação e expressão (TICE) em espaços escolares públicos. Neste texto, o objetivo 
é apresentar percepções de docentes e discentes sobre as Redes Sociais de Comunicação, como um meio pedagógico auxiliador de estratégias de estudos na organização do trabalho docente e discente. Em outras palavras, busca-se compreender as formas de acesso aos canais de comunicação digitais, suas possibilidades pedagógicas e as maneiras em que estão sendo apropriados nos afazeres escolares, nos aspectos de organização do trabalho docente e discente e apreensão dos recursos tecnológicos e comunicacionais digitais no espaço escolar, como ferramentas auxiliadoras de ensino e aprendizagens.

\section{Metodologia}

O percurso metodológico caracteriza uma pesquisa exploratória com abordagem qualitativa, voltada para compreender o fenômeno estudado. Os dados apresentados foram construídos por meio de diálogo da revisão bibliográfica com as respostas de questionários semiestruturados (CRESWELL, 2007; TRIVIÑOS, 2008; FLICK, 1999).

Os questionários semiestruturados tinham por objetivos: i) mapear as maneiras pelas quais os sujeitos investigados realizam o acesso, a familiaridade tecnológica e a imersão nos recursos digitais; e ii) desvelar percepções e maneiras que fazem (ou não) do ambiente digital um meio pedagógico auxiliador de estratégias de estudos, na organização do trabalho docente e discente, na ampliação das relações entre aluno-professor e na construção de uma nova forma de aprendizagem coletiva.

O locus da pesquisa de campo foi o Centro de Ensino Médio da Rede Pública do Sistema de Ensino do Estado do Tocantins, localizado no município de Araguaína. A aplicação aconteceu nos primeiros semestres dos anos de 2013 e 2016. Foram aplicados 120 questionários a discentes pertencentes a quatro turmas de $3^{\mathrm{a}}$ série, nos turnos matutino e vespertino; e 20 a docentes (efetivos ou contratados), ministrantes de aulas nas áreas de conhecimento de Ciências da Natureza (Biologia, Química, Física e Matemática), Linguagens e Códigos (Língua Portuguesa, Arte, Inglês, Espanhol e Educação Física) e Ciências Humanas (História, Geografia, Sociologia e Filosofia).

Com base na revisão bibliográfica de autores que discutem temáticas relacionadas à educação e Tecnologias da Comunicação e Informação (TICE), na organização, análise e interpretação dos dados e das informações coletadas nos questionários, o artigo traz à luz reflexões que estabelecem um diálogo profícuo entre educação e tecnologias, 
favorecendo o reconhecimento e a análise das múltiplas percepções dos participantes da pesquisa (FLICK, 1999).

Nessa perspectiva, o trabalho estrutura-se, além das seções anteriores, na conceituação de cibercultura e redes sociais no entrelaçamento com as questões educacionais; na apresentação, análise e interpretação dos achados parciais da pesquisa; e em considerações finais.

\section{Cibercultura, Redes Sociais e Educação}

Nos últimos anos que encerram o século XX e nos primeiros que inauguram o século XXI, pesquisadores, como Levy (1999) e Harvey (1999), discutem acerca das maneiras pelas quais a vida, na dita sociedade pós-moderna, ou das tecnologias da comunicação, emoldura seus olhares em experiências de mobilidade tecnológica, assentada na instantaneidade e circulação das informações, alterando substancialmente o campo da percepção no que tange aos conceitos de tempo e espaço. Um novo ordenamento temporal, sacramentado pelas tecnologias de comunicação e informação, consagra-se com a expansão da Internet, cuja característica singular encontra-se na substituição, em forma de conexão, das noções de tempo/duração em tempo/velocidade e no estabelecimento de relações sociais instantâneas.

Kerckhove (2009, p. 201) contribui com a discussão sobre a investigação da nova realidade eletrônica, quando chama atenção sobre a existência de uma "consciência global" que hibridiza as noções de espaço público e privado, superando a ideia e imagem de uma "aldeia global" antes introduzida por Marshall McLuhan (1998). Tais princípios encontravam-se nas identidades e locais determinados, com comunidades vivendo em diferentes velocidades e níveis de experiências sociais destituídas de mediação, embora fôssemos pertencentes e aldeões da mesma Terra.

Com a Internet, a cultura passa a constituir-se sob o tecido da implosão das distâncias e o estreitamento entre espaços; o controle da linguagem torna-se público e oral, como escreve Kerckhove (2009, p. 205):

Mudou da Idade Média para a Idade da Razão e agora está mudando para a Idade da Mente. Na era do livro, o controle da linguagem foi sempre privado, mas com as mídias eletrônicas o controle da linguagem torna-se público e oral. Com o advento da Internet temos o primeiro meio oral e escrito, privado e público, individual e coletivo ao mesmo tempo. A ligação entre mente pública e privada é feita através das redes abertas e conectadas do Planeta. 
Levy (1999, p. 17) analisa essas mesmas transformações nas relações humanas quando anuncia a onipresença da chamada cibercultura, traduzida como "[...] um conjunto de técnicas (materiais e intelectuais), de práticas, de atitudes, de modos de pensamento e de valores que se desenvolvem justamente com o crescimento do ciberespaço".

\begin{abstract}
A cibercultura é a expressão da aspiração de construção de um laço social, que não seria fundado nem sobre links territoriais, nem sobre relações institucionais, nem sobre relações de poder, mas sobre a reunião de centros de interesses comuns, sobre o jogo, sobre o compartilhamento do saber, sobre a aprendizagem colaborativa, sobre processos abertos de colaboração. (LÉVY, 1999, p. 130).
\end{abstract}

A cibercultura é a vida construída por meio das redes sociais digitais, em meio aos inúmeros processos interativos e participativos. Por meio dessas redes, são construídas subjetividades e sociabilidades e redesenhados nossos modos de ser e viver.

O ciberespaço, também passou a ser chamado, simplesmente, de "Rede", um meio de comunicação originário da interconexão mundial dos computadores (CASTELLS, 1999).

A consolidação das Redes Sociais, em uma perspectiva sociológica, ampara-se nos princípios de reciprocidade, partilha e confiança, estabelecidos entre indivíduos, grupos e seus pares. No entanto, a definição de Redes Sociais, também, pode ser compreendida como escreve Recuero (2009, p. 24):

\footnotetext{
Um conjunto de dois elementos: atores (pessoas, instituições ou grupos; os nós da rede) e suas conexões (interações ou laços sociais) [...] uma rede, assim, é uma metáfora para observar os padrões de conexão de um grupo social, a partir das conexões estabelecidas entre os diversos atores. A abordagem da rede tem, assim, seu foco na estrutura social, onde não é possível isolar os atores sociais e nem suas conexões.
}

Denota-se, assim, que as formas, pelas quais as sociedades contemporâneas têm se organizado, confirmam o entrelaçamento em que as Redes Sociais vêm, silenciosamente, tecendo com os fazeres dos sujeitos e o papel desempenhado nas instituições, as posturas docentes e discentes em face da inserção dos dispositivos tecnológicos digitais (notebooks, tablets, ipads, celulares com acesso à Internet, smartphones) na rotina das unidades educacionais. Nesse sentido, Bohn (2009, p. 1) reforça que 


\begin{abstract}
Assim como as ferramentas da Web 2.0, as redes sociais oferecem um imenso potencial pedagógico. Elas possibilitam o estudo em grupo, troca de conhecimento e aprendizagem colaborativa. Uma das ferramentas de comunicação existentes em quase todas as redes sociais são os fóruns de discussão. Os membros podem abrir um novo tópico e interagir com outros membros compartilhando ideias [...]. Enfim, com tanta tecnologia e ferramentas gratuitas disponibilizadas na Web, cabe ao professor o papel de saber utilizá-las para atrair o interesse dos jovens no uso dessas redes sociais favorecendo a sua própria aprendizagem de forma coletiva e interativa.
\end{abstract}

O uso das ferramentas digitais, como alerta o autor, expressa não só as maneiras pelas quais o acesso e o compartilhamento de conhecimentos por meio da imersão nas Redes Digitais vêm se consolidando como extensão do espaço pedagógico e da atuação escolar, mas também, anuncia as maneiras diversificadas em que componentes curriculares e o desenvolvimento de metodologias comunicacionais interativas emergem em resposta ao que a cultura juvenil contemporânea tem exigido do exercício do magistério, em especial, no Ensino Médio.

Ainda sobre essa discussão, Kenski (2012) ressalta que no cenário atual - em especial na Educação - verifica-se, também, a presença de um tempo das urgências, volatilidades, da perturbação na percepção da realidade e do outro em forma fugaz de aparição/desaparição das coisas nas telas. Assim, as estratégias metodológicas, práticas e posturas pedagógicas mediadas por tecnologias digitais transitam entre a organização e a estrutura analógica da escola. Essa mesma realidade passa a ser uma condição inusitada em que as relações dos e entre os fenômenos é a imagem de um presente interminável em que cada um promove a sua performance existencial e coletiva.

Tal condição de vida altera, significativamente, as perspectivas tradicionais e receios que faziam, e de certo modo, ainda fazem parte do mundo menos conectado da maioria dos adultos, pais, mães e professores. Umas dessas principais mudanças é que a mídia, atualmente, não é mais algo que se consome, mas aquilo que se produz e difunde, deixando de ser influenciadora e condicionadora de tendências, para solicitar, exaltar e festejar a participação e a colaboração, instaurando, assim, uma economia da dádiva entre os internautas.

Criatividade e generosidade são valores típicos da era das conexões e a cibercultura juvenil não cessa de exaltar esses valores fundamentais. Shirky (2011) defende que a cultura da generosidade mostra os meios que temos para fazer a diferença e melhorar o mundo. A conectividade exige e valoriza esse fazer com o outro. 
Diante do exposto, referente às mudanças ocasionadas, sobretudo, pelo surgimento da Internet e sua expansão planetária, é que este trabalho apresenta percepções de docentes e discentes acerca das Redes Sociais de Comunicação, como um meio pedagógico auxiliador de estratégias de estudos na organização do trabalho docente em um Centro de Ensino Médio da Rede Pública do Sistema Estadual de Ensino do Tocantins.

Múltiplos olhares: a percepção de docentes e discentes acerca do uso pedagógico das Redes Sociais de Comunicação na escola

Em se tratando de mapear as maneiras pelas quais os sujeitos investigados realizam o acesso, a familiaridade tecnológica e a imersão nos recursos digitais, importa caracterizar que o Centro de Ensino Médio da Rede Estadual de Ensino do Estado do Tocantins, município de Araguaína, conta com os seguintes espaços e insumos, a saber: um laboratório de informática, contendo vinte máquinas oriundas do Programa de Informatização das Escolas Públicas (PROINFO), porém, com apenas doze em condições adequadas de uso pela comunidade escolar, mesmo possuindo conexão banda larga, essa não foi citada como alternativa para o acesso à Internet pelos sujeitos participantes da pesquisa. Há, também, para os servidores (equipe gestora, pedagógica, administrativa e docente) rede de acesso à Internet sem fio, não sendo disponibilizado login/senha aos alunos, por recomendação da Diretoria Regional de Ensino, por considerar frágil o sistema de proteção de dados oferecido pelo provedor da Secretaria Estadual da Educação.

Para desvelar as percepções e maneiras que fazem (ou não) do ambiente digital um meio pedagógico auxiliador de estratégias de estudos, na organização do trabalho docente e discente, na ampliação das relações entre aluno-professor e na construção de uma nova forma de aprendizagem coletiva, os dados e as informações coletados junto aos docentes revelaram:

a) Compreendem o que é Rede Social, $100 \%$, porém, apenas $60 \%$ possuem perfil.

b) Os acessos se dão, principalmente, por meio de notebook, desktop, e somente $50 \%$ via celular; 
c) O tempo de permanência online, oscila entre 1 e 2 horas, com exceção, nos períodos de divulgação de médias bimestrais e registro de diários;

d) $20 \%$ utilizam as Redes Sociais para publicarem conteúdos trabalhados em sala de aula, ou mesmo, disponibilizar atividades complementares, gabaritos, orientações acerca de trabalhos, divulgação de aulas-extras e datas de avaliação;

e) $65 \%$ são favoráveis à construção de um perfil da escola nas Redes Sociais, contanto que não acarrete exigências funcionais e a alimentação de dados seja realizada pela equipe pedagógica e administrativa;

f) A área de conhecimento que recorrentemente faz uso das Redes Sociais, como canal de interação com os discentes, é a de Ciências Exatas (Matemática, Biologia e Física). Nas demais áreas, somente um docente da disciplina de História e um de Língua Portuguesa, também, adotam essa prática docente;

g) Acreditam que as Redes Sociais não passam de puro entretenimento e, portanto, exporiam de maneira incontornável suas vidas pessoais, 40\%;

h) Acessam informações referentes a cursos de aperfeiçoamento profissional, pós-graduação, conteúdos que, posteriormente, usam em seus planejamentos e em sala de aula, apenas $30 \%$.

Em se tratando dos discentes, os dados e as informações revelaram:

a) Em $100 \%$ dos questionários, houve a confirmação sobre saberem o que é uma Rede Social e como esta é presente em seu cotidiano pessoal e escolar como veículo de comunicação e aprendizado;

b) Embora estando no período de aulas, mantêm o status online, atualizando seus registros a cada 50, 60 minutos, sendo o mesmo tempo de duração de cada aula;

c) Quanto às formas de acesso à Internet em 95\% das respostas apresenta que se dá via celular, sendo $50 \%$ desses modelos smarthfones ou tablets;

d) Permanecem, em média, conectados até $3 \mathrm{~h}$ (computador pessoal) e mais de $12 \mathrm{~h}$ (celular); 
e) Participam da Rede Social Facebook, 98\% e apenas 2\% ainda não possuem perfil, por residirem em assentamento, sem acesso à Internet ou o aparelho celular, que possuíam, não apresenta o aplicativo;

f) $80 \%$ utilizam, diariamente, seus contatos da Rede Social para: informarem-se acerca de conteúdo aplicado, de datas de avaliações, do calendário escolar;

g) $90 \%$ sugerem a criação de um perfil da escola nas Redes Sociais, pois consideraram que estariam mais informados quanto às atividades culturais promovidas pela comunidade escolar, mural de avisos, início e retorno do semestre letivo, entrega de notas, orientações acerca de documentação, conteúdos, banco de provas do Exame Nacional do Ensino Médio (ENEM), horário de funcionamento da escola, quantidade de vagas disponíveis para matrículas, regimento escolar e quadro de professores por disciplina;

h) $\quad 80 \%$ nunca compartilham - em seus perfis - vídeo-aulas, slides, links, com seus contatos. No entanto, gostariam que estes conteúdos fossem divulgados pelos seus docentes, durante suas aulas, em especial, das disciplinas de Língua Portuguesa, Matemática, Física e Química, ou que houvesse uma monitoria online;

i) $80 \%$ desconhecem a existência de aplicativos (jogos, calendários, eventos, calendário, mural, editor de grupos e textos) presentes dentro da Rede Social por eles eleita como a que mais utilizam;

j) $85 \%$ destacam que a divulgação de gabaritos e envio de atividades extras por uma parcela mínima de professores que utilizam o e-mail da turma, auxiliam na aprendizagem e os levam a se sentirem envolvidos com a disciplina.

Diante dos dados e das informações apresentados e das análises que emergiram, infere-se, primeiramente, que, a cada dia, os processos de formação que ocorrem no interior das salas de aulas, passam pela necessidade em se considerar que os múltiplos espaços-tempos estão vertiginosamente sendo potencializados pelos usos das tecnologias de comunicação digitais (SANTAELLA, 2010), encontrando ancoradouro no uso diário 
dos dispositivos móveis, via digital em rede, por parte significativa de discentes e, ainda, de maneira tímida, pelos docentes.

Por conseguinte, a existência de nativos e imigrantes digitais, quando transposta para o âmbito escolar, aponta que docentes e discentes, embora convivam no mesmo espaço em alguns aspectos, apresentam olhares divergentes quanto ao trato com os artefatos tecnológicos móveis, na perspectiva pedagógica do uso das Redes Sociais como canal alternativo de comunicação, organização do trabalho escolar, do trabalho pedagógico, interação entre corpo docente e discente. No entanto, convergem seus olhares quando registram não saberem utilizar ou não utilizarem os recursos/aplicativos presentes nas vias digitais de forma pedagógica e com a finalidade de potencializar os processos de aprendizagem e posturas didático-metodológicas propiciadas por essas tecnologias de acesso e conexão. Deste modo, demonstram desconhecimento ou mesmo certo "analfabetismo funcional tecnológico".

Portanto, na timeline de docentes e discentes, abrigam-se silenciosos ou invisíveis às suas percepções tecnologias de inteligência capazes, não só de alterar completamente as maneiras tradicionais de armazenamento, domínio e diálogo com as informações, quanto de favorecer o aprimoramento da leitura, escrita e linguagem. Sibilia (2012), a esse respeito, inquieta-se questionando acerca das Redes ou paredes na escola em tempos de dispersão.

\section{Considerações finais}

Tendo por objetivo apresentar percepções de docentes e discentes sobre as Redes Sociais de Comunicação, como um meio pedagógico auxiliador de estratégias de estudos na organização do trabalho docente e discente, as análises dos dados e das informações trazem elementos para que a investigação no cotidiano escolar promova a compreensão acerca dos aspectos derivados das condições promovidas pelas tecnologias de comunicação simultânea, pois afetam, direta e indiretamente, as formas de educar, aprender e os agentes nelas envolvidos.

Em certa medida, os dados apontam, também, para o descompasso na falta de familiaridade tecnológica presente no dia a dia escolar, demonstrada por docentes e discentes, docentes e áreas de conhecimentos. Emergem dos dados questões atuais que merecem uma investigação mais acurada, o que ocorrerá na segunda etapa de pesquisa, 
no segundo semestre de 2019, as quais contemplarão o campo da prática docente no que diz respeito à apropriação dos dispositivos móveis digitais como as novas plataformas comunicacionais digitais.

É importante enfatizar que tais dispositivos se fazem presentes nos bolsos e mãos de nativos e imigrantes digitais atrelados ao estabelecimento de estratégias pedagógicas inovadoras agora alicerçadas nos suportes eletrônicos digitais; no possível reordenamento no tocante ao tempo de aprender, seus espaços por excelência, ao exercício de elaboração/produção de conhecimentos agora pelo viés do denominado multiletramento digital e no estabelecimento de uma mediação pedagógica que ultrapassa os muros das escolas, mas que, no entanto, se encontra ancorada nos nós divergentes e convergentes das redes sociais.

\section{Referências}

BOHN, V. As redes sociais no ensino: ampliando as interações sociais na web. RBLA: Belo Horizonte, v. 15, n. 3, p. 735-760. Disponível em: httpp://www.conexãoprofessor.rj.go.br/temas-especiais. Acesso em: 12 dez. 2014.

CASTELLS, M. A sociedade em rede a era da informação: economia, sociedade e Cultura. São Paulo: Paz e Terra, 1999.

CRESWELL, J. W. Projeto de pesquisa: método qualitativo, quantitativo e misto. Porto Alegre: Artmed, 2007.

FLICK, U. Introdução à pesquisa qualitativa. 3. ed. Porto Alegre: Artmed, 2009.

HARVEY, D. Condição pós-moderna: uma pesquisa sobre as origens da mudança cultural. São Paulo: Estação Liberdade, 1999.

KENSKI, V. M. Tecnologias e tempo docente. Campinas, SP, 2012.

KERCKHOVE, D. A pele da cultura. Lisboa. Olho D’água, 2009.

LÉVY, P. Cibercultura. Rio de Janeiro, RJ: Editora 34, 1999.

MCLUHAN, M. Os meios de comunicação como extensão do homem. São Paulo. Cultrix, 1998.

PRENSKI, M. Nativos e imigrantes digitais. On the Horizon (University Press), v. 9, n. 5, 2001. Disponível em: http://www.marcprensky.com/writing. Acesso em: 13 out. 2015.

RECUERO, R. Redes sociais na internet. Porto Alegre: Sulina, 2009. 
ROJO, R. Multiletramentos na escola. São Paulo: Parábolas Editoriais, 2012.

SANTAELLA, L. Aprendizagem ubíqua substitui a educação formal? Revista de Computação e Tecnologia da PUC-SP, v. 2, n. 1, 17-22, 2010. Disponível em: https://revistas.pucsp.br/index.php/ReCET/article/viewFile/3852/2515. Acesso em: 13 out. 2015.

SHIRKY, C. A cultura da participação: criatividade e generosidade no mundo conectado. Rio de Janeiro: Zahar, 2011.

SIBILIA, P. Redes ou paredes: a escola em tempos de dispersão. Rio de Janeiro, Editora Contraponto, 2012.

TAPSCOTT, D. Geração digital: a crescente e irresistível ascensão da Geração Net. São Paulo: Makson Books, 1999.

TRIVIÑOS, A. Introdução à pesquisa em ciências sociais. 17. reimpressão. São Paulo: Atlas, 2008. 